Article

\title{
Effectiveness of Prophylactic Human Papillomavirus Vaccine in the Prevention of Recurrence in Women Conized for HSIL/CIN 2-3: The VENUS Study
}

\author{
Andrea Casajuana-Pérez ${ }^{1, *}$, Mar Ramírez-Mena ${ }^{2}$, Estefanía Ruipérez-Pacheco ${ }^{2}$ (D), Inés Gil-Prados ${ }^{2}$, \\ Javier García-Santos ${ }^{2}$, Mónica Bellón-del Amo ${ }^{2}$, Juan J. Hernández-Aguado ${ }^{3}$, Jesus de la Fuente-Valero ${ }^{3}$, \\ Ignacio Zapardiel ${ }^{4}$ (D) and Pluvio J. Coronado-Martín ${ }^{2}$ (D)
}

check for updates

Citation: Casajuana-Pérez, A.; Ramírez-Mena, M.; Ruipérez-Pacheco, E.; Gil-Prados, I.; García-Santos, J.;

Bellón-del Amo, M.; Hernández-Aguado, J.J.; de la Fuente-Valero, J.; Zapardiel, I.; Coronado-Martín, P.J. Effectiveness of Prophylactic Human Papillomavirus Vaccine in the Prevention of Recurrence in Women Conized for HSIL/CIN 2-3: The VENUS Study. Vaccines 2022, 10, 288. https:// doi.org/10.3390/vaccines10020288

Academic Editor: Yutaka Ueda

Received: 9 January 2022

Accepted: 11 February 2022

Published: 14 February 2022

Publisher's Note: MDPI stays neutral with regard to jurisdictional claims in published maps and institutional affiliations.

Copyright: (c) 2022 by the authors. Licensee MDPI, Basel, Switzerland. This article is an open access article distributed under the terms and conditions of the Creative Commons Attribution (CC BY) license (https:// creativecommons.org/licenses/by/ $4.0 /)$.
1 Department of Obstetrics and Gynecology, University Hospital 12 de Octubre, 28041 Madrid, Spain

2 Gynecology Oncology Unit, Institute of Women's Health, San Carlos Clinical Hospital (IdISSC), Complutense University, 28040 Madrid, Spain; marramirezmena@gmail.com (M.R.-M.); estefania.ruiperez@salud.madrid.org (E.R.-P.); inesgilpra@gmail.com (I.G.-P.); javiergsantos@yahoo.es (J.G.-S.); monica.bellon@salud.madrid.org (M.B.-d.A.); pluviojesus.coronado@salud.madrid.org (P.J.C.-M.)

3 Service of Obstetrics and Gynecology, Infanta Leonor Hospital, Complutense University, 28040 Madrid, Spain; jjhernandeza@salud.madrid.org (J.J.H.-A.); delavalero@gmail.com (J.d.l.F.-V.)

4 Gynaecologic Oncology Unit, La Paz University Hospital-IdiPAZ, 28046 Madrid, Spain; ignaciozapardiel@hotmail.com

* Correspondence: andreamercedes.casajuana@salud.madrid.org

\begin{abstract}
Background: Recent data have shown that the human papillomavirus (HPV) vaccine could impact on a decrease in high-grade cervical intraepithelial lesions (HSIL) in women who have undergone surgical treatment. This study aimed to evaluate the efficacy of human papilloma virus (HPV) vaccination against persistent/recurrent disease in patients undergoing conization for high-grade squamous intraepithelial lesion/cervical intraepithelial neoplasia-grade 2-3 (HSIL/CIN 2-3). Methods: From January 2009 to March 2019, 563 patients with HSIL/CIN 2-3 underwent conization. The population was divided into two groups according to vaccination status: vaccinated-group (V-Group) and non-vaccinated-group (NV-Group). Bivalent or quadrivalent vaccines were administered indiscriminately. A follow-up was scheduled every 6-12 months according to clinical guidelines. The mean follow-up was 29.6 vs. 36.5 months in the V-group and NV-group, respectively. Results: 277 (49.2\%) women were vaccinated, while 286 (50.8\%) were not. Overall, persistent/recurrent HSIL/CIN 2-3 was presented by $12 / 277$ (4.3\%) women in the V-Group and 28/286 (9.8\%) in the NV-Group (HR: $0.43,95 \%$ Confidence interval $0.22-0.84, p=0.014)$. Vaccination was associated with a $57 \%$ reduction in HSIL persistence/recurrence after treatment. When no disease was present in the first 6-month follow-up visit, persistence/recurrence rates were very low in both groups: $1.1 \%$ in the V-Group vs. $1.5 \%$ in the NV-Group $(p>0.05)$. The factor associated with a high-risk of HSIL persistence/recurrence was the presentation of a positive co-test in the first control after treatment $(p<0.001)$. Conclusions: Our results corroborate the benefit of HPV vaccination in woman treated for HSIL/CIN 2-3, showing a reduction of persistent/recurrent HSIL/CIN 2-3.
\end{abstract}

Keywords: HPV vaccine; conization; subsequent disease; persistent/recurrent disease; HSIL/CIN 2-3; cervical cancer prevention

\section{Introduction}

Persistent High Risk-Human Papillomavirus (HR-HPV) infections are strongly associated with the development of High-grade Squamous Intraepithelial Lesion/Cervical Intraepithelial Neoplasia (HSIL/CIN) 2-3 [1,2]. Prophylactic vaccination against HPV with either of any type of the vaccine (bivalent, quadrivalent, nonavalent) has been demonstrated to be the best primary prevention strategy against this disease [3,4]. 
Patients who have received excisional therapy (conization) for HSIL/CIN 2-3 have a $0.4-19 \%$ risk of lesion recurrence [5]. In addition, these women have a $5-10$-fold higher risk of developing cervical cancer over the following 10-20 years compared with the general population [6,7]. There is a growing body of evidence showing that prophylactic vaccination against HPV in women who have been treated for Squamous Intraepithelial Lesions (SIL)/CIN may result in a reduction in subsequent disease during follow-up [8-11]. In addition, it seems that, immunologically, women undergoing a Loop Electrosurgical Excision Procedure (LEEP) showed some changes in inflammatory response in the cervix, reducing TNFa and pro-inflammatory cytokines because surgical intervention eliminates the lesion persistently infected with HPV $[12,13]$. The anti-inflammatory microenvironment disadvantages a persistent HPV infection. Therefore, if the vaccine were applied at this time, new or recurrent HPV infections could be prevented [14].

In April 2015, the Community of Madrid pioneered an HPV vaccination strategy in patients under 45 years of age with a diagnosis of HSIL/CIN 2-3 who had undergone conization in the previous 3 years. The Gynaecology Oncology Department of the San Carlos Clinical Hospital was among the first centers to benefit from initiating prophylactic vaccination against HPV in treated women. In the last 5 years, different Spanish regions have incorporated free prophylactic vaccination against HPV for women treated for HSIL/CIN 2-3. Since October 2018, the Ministry of Health has supported the Adult Vaccination Calendar for risk groups [15]. In this calendar, prophylactic vaccination against HPV is included for certain risk groups, including women treated for HSIL/CIN 2-3 regardless of age. This strategy had already been implemented in the Community of Madrid in March 2019.

The primary objective of this study was to evaluate the efficacy of HPV vaccination against persistent/recurrent disease (subsequent disease) in patients undergoing conization for HSIL/CIN 2-3 in a real-life setting. For this purpose, a group of treated and vaccinated women were compared with an unexposed group of treated and non-vaccinated women. Secondary objectives were: (1) to analyze the risk of subsequent disease in women with a negative co-test at the 6-month follow-up visit after treatment, and (2) to evaluate the predictive factors of lesion recurrence after excisional therapy for HSIL/CIN 2-3.

\section{Materials and Methods}

\subsection{Study Design}

A retrospective cohort study of women treated by excisional therapy for HSIL/CIN 2-3 was carried out at Hospital Clínico San Carlos between 2009-2019.

The study consecutively included women who met the following inclusion criteria and none of the exclusion criteria:

Inclusion criteria: (1) women older than 18 years who had received excisional therapy for histologically confirmed HSIL/CIN 2-3; (2) women who provided signed informed consent; and (3) women attending the first post-surgery control.

Exclusion criteria: (1) women who do not wish to or cannot provide informed consent; (2) women who do not comply with the study requirements; (3) conized women with lesions other than HSIL/CIN 2-3 (cervix carcinoma, persistent LSIL/CIN 1 with lesion $\leq$ LSIL/CIN 1 in cone specimen); and (4) women with immunosuppression. All the women included, regardless of the group analyzed, were diagnosed by the same medical team and managed according to the local clinical guidelines adapted from the Spanish Association of Cervical Pathology and Colposcopy (AEPCC) and the Spanish Society of Gynaecology and Obstetrics (SEGO) $[4,7,16]$.

Patients diagnosed with HSIL/CIN 2-3 were referred to HPV vaccination. As the vaccine began to be funded in 2015, most women diagnosed from 2009-2014 were not vaccinated, while those diagnosed from 2015-2019 were. Women who had received at least one dose of the HPV vaccine were considered as vaccinated. 


\subsection{Sample Study}

Liquid-based cytology and HPV testing were performed in cervical samples that had been previously collected using a cytobrush and stored in PreservCyt solution. After preparing cytology in slides, it was stained with the Papanicolaou method. The sample was classified using the Bethesda 2014 nomenclature.

The detection of HPV was performed by liquid-based cytology using the CLART TEST PAPILLOMAVIRUS HUMAN test that detects the presence of the HPV virus $(6,11,16$, $18,26,31,33,35,39,40,42,43,44,45,51,52,53,54,56,58,59,61,62,66,68,70,71.72,73$, $81,82,83,84,85$ and 89$)$. The test has a diagnostic sensitivity and specificity of $98.2 \%$ and $100 \%$, respectively, and an analytical specificity of $100 \%$. The analytical sensitivity of this test is $100 \%$ when the number of copies is 1000 or 10,000 depending on the type of HPV. The laboratory carried out an external quality control according to the Spanish Society of Pathological Anatomy (SEAP) [17].

\subsection{Pre-Surgical Evaluation}

Patients with an abnormal cytological result and/or a positive HPV test were referred to the Gynaecology Oncology Unit of our hospital for evaluation according to the Cervical Cancer Prevention Guidelines. Patients diagnosed with HSIL/CIN 2-3 or persistent LSIL/CIN 1 underwent cervical conization. Patients who met the inclusion criteria were subsequently enrolled in the study. Women who attended follow-up visits signed the informed consent approved by the local Ethics Commission (24/09/20; 19/320-E).

\subsection{Surgical Treatment}

Cervical LEEP was carried out by minor outpatient surgery under local analgesia and sedation. After infiltration with a local anesthetic and vasoconstrictor in the 4 quadrants of the cervix, conization with a diathermic loop was performed under direct colposcopy vision. The size of the loop varied according to the type of conization and the characteristics of the lesion. Immediate endocervical curettage was performed in all cases as well as selective coagulation of the bleeding areas. Cervical specimens were anatomically oriented, placed in formaldehyde, and sent to Pathological Anatomy for study. All the procedures were performed by members of the Gynaecology Oncology Department, who are experts in the LEEP technique.

\subsection{Clinical Follow Up}

The first assessment was made 30 days after surgery to review the pathology results. Positive margins were diagnosed when a SIL/CIN of any grade involved any edge, or the endocervical curettage was positive.

According to the follow-up protocol of the 2014 Cervical Cancer Prevention Clinical Guide of the AEPCC prevailing at the time of the study, in cases of non-involvement of margins and negative endocervical curettage, the first post-surgery control was carried out with co-testing determination 6 months after conization. In the case of positive endocervical curettage or margin involvement, the first post-surgery control was at 4 months with cotesting, endocervical study, and colposcopy. Subsequently, a new co-test was carried out at 12,24 , and 36 months after the first post-surgery control in patients with previous negative results. After 3 years of negative testing, the patient was returned to the current cervical cancer-screening program. In women with abnormal co-testing at six months, follow-up varied according to the results and colposcopy findings.

The 6-month follow-up visit was defined according to the co-testing result as: (1) persistent lesion (presence of any lesion by cytology or biopsy); (2) persistent HPV infection (presence of HR-HPV); or (3) absence of disease (negative cytology/biopsy and negative determination for HR-HPV).

The clinical outcome of the women at the end of the follow-up was categorized as follows: (1) persistence/recurrence: positive HR-HPV test result and/or presence of histological or cytological SIL/CIN of any grade at a cervical or vaginal location; (2) no 
disease: negative HR-HPV test and negative Pap test/biopsy. ASCUS lesion is only considered if it is accompanied by HR-HPV infection.

Follow-up was defined as the time from conization to the diagnosis of persistence/recurrence or to the last recorded visit.

\subsection{Vaccination Status}

In 2013, vaccination began to be recommended in patients treated for HSIL/CIN 2-3, although vaccination funding was not included in the national system. Madrid was one of the first regions to support funded vaccination for these patients in 2015, with patients diagnosed with HSIL/CIN 2-3 being referred to their primary care center for vaccination. The bivalent vaccine [2v-HPV] (against genotypes 16/18) or quadrivalent vaccine [4v-HPV] (against genotypes 6,11,16 and 18) was administered indiscriminately, depending on the funding policies prevailing at that time. Patients vaccinated with at least one dose of any of the available vaccines were considered as cases. The $2 \mathrm{v}$ vaccine had a vaccination schedule of 0-1-6 months, while the $4 \mathrm{v}$ was administered at 0-2-6 months.

The vaccination status at conization (defined by the date of administration of the first dose close to the treatment date), as well as the dates of administration of each dose, were collected from the patients' records.

\subsection{Ethical Approval}

The study was carried out according to the Guidelines to Good Clinical Practice of the International Conference on Harmonization and the Declaration of Helsinki. Enrolled patients signed an informed consent during follow-up visits. The study was carried out according to the clinical protocols of the hospital, without any additional procedures. The study was approved by the Ethics Committee of our institution (Number 19/320-E).

\subsection{Data Analysis}

Quantitative variables are expressed with their mean and standard deviation (SD). Variables showing an asymmetric distribution were expressed with the median and interquartile range (IQR). The association of qualitative variables between the two study groups was compared using the $\chi 2$ or Fisher exact test. Quantitative variables were compared by the Student's T or the Mann-Whitney U test according to the distribution.

The Kaplan-Meier method was used to estimate the distribution of persistence/recurrence in the study groups. A univariate Cox regression analysis was used to find the variables associated with HSIL/CIN 2-3 persistence/recurrence. For all tests, a $p$ value less than 0.05 was considered as significant. The data were analyzed with IBM-SPSS software 21.0.

\section{Results}

\subsection{Population Characteristics}

From January 2009 to January 2019, 563 patients were evaluable and included in the study (See Figure 1).

Table 1 shows the characteristics of the study population. The 33 patients treated for persistent LSIL/CIN1 presented a final histological result of HSIL/CIN 2-3 in the cone specimen. A negative result in the conization specimen was found in 34 patients treated by punch biopsy of HSIL/CIN 2-3: 26 were from biopsies with HSIL/CIN2 and 8 with HSIL/CIN3 results. A final diagnosis of LSIL/CIN 1 was found in the cone specimen in 61 women: 49 had had a previous HSIL/CIN2 biopsy and 13 HSIL/CIN3. All these cases were considered as HSIL/CIN 2-3 cases in the analysis.

Positive margins in the cone specimen were found in 131 women (23.4\%): 72 involved only endocervical margins, 42 only exocervical, and 17 involving both margins. Of these 131 women, 29 underwent a second conization because of involvement of the endocervical margin, and only one woman continued to show positive margins in the re-conization specimen, being considered as a positive margin for the follow-up. Finally, 103 (18.3\%) women were considered as having positive margins during the follow-up period. 


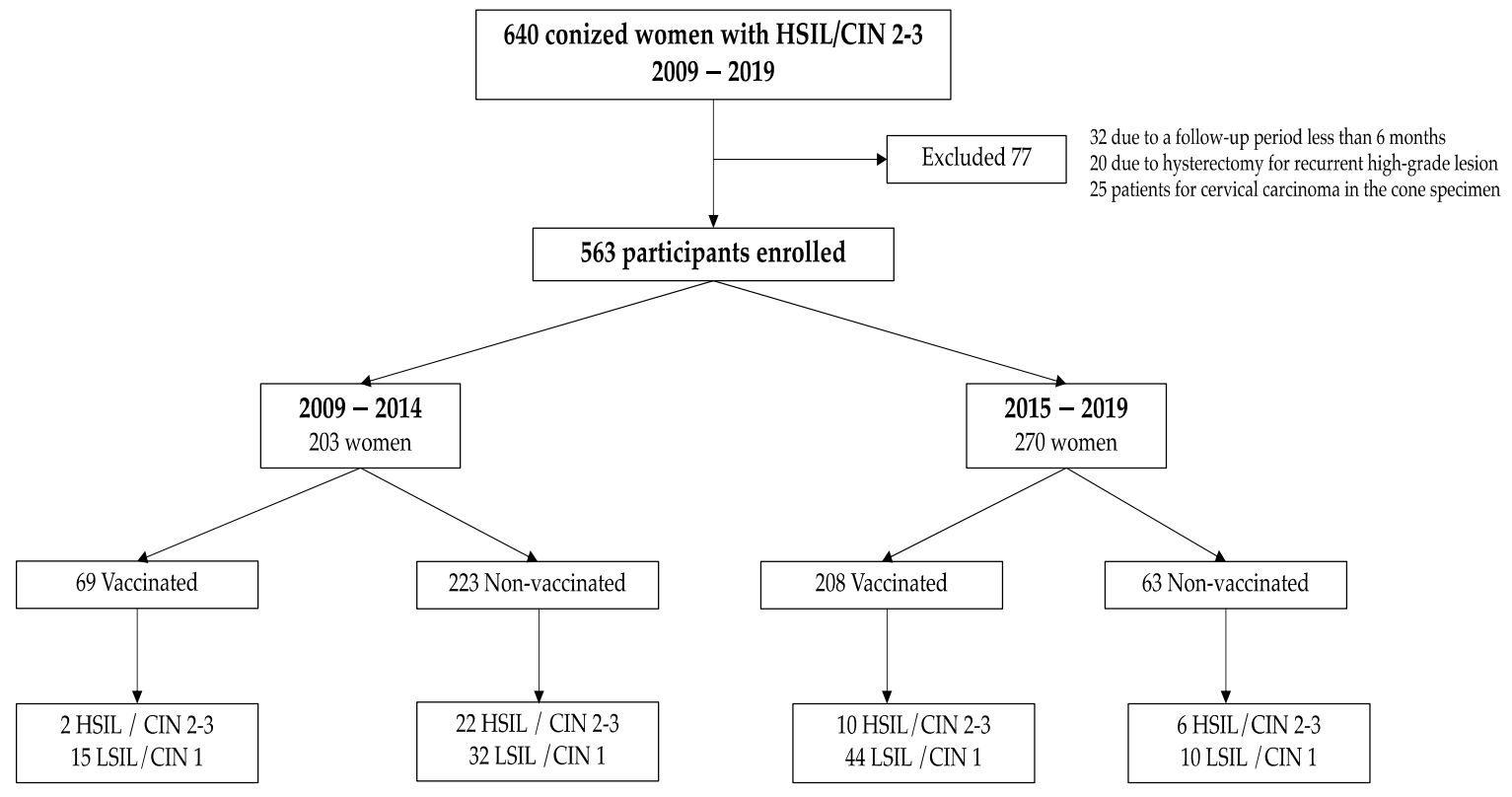

Figure 1. Participant disposition. Abbrevations: CIN: Cervical Intraepithelial Neoplasia. HSIL: High-grade Squamous Intraepithelial Lesion. LSIL: Low-grade Squamous Intraepithelial Lesion.

Table 1. Clinical characteristics and data referring to conization in vaccinated and non-vaccinated women. CIN: Cervical Intraepithelial Neoplasia. HPV: Human Papilloma Virus. HR: High Risk HSIL: High-grade Squamous Intraepithelial Lesion. LSIL: Low-grade Squamous Intraepithelial Lesion.

\begin{tabular}{|c|c|c|c|}
\hline Clinical Characteristics & $\begin{array}{c}\text { Vaccinated Group }(\%) \\
(n=277)\end{array}$ & $\begin{array}{c}\text { Non-Vaccinated } \\
\text { Group }(\%)(n=286)\end{array}$ & $p$ \\
\hline \multicolumn{4}{|l|}{ Age } \\
\hline$<35$ years & $128(46.2)$ & $109(38.2)$ & \multirow{2}{*}{0.060} \\
\hline$\geq 35$ years & $149(53.8)$ & $176(61.8)$ & \\
\hline \multicolumn{4}{|l|}{ Smokers } \\
\hline No & $122(44)$ & $118(41.3)$ & \multirow{3}{*}{0.077} \\
\hline Yes & $61(22)$ & $47(16.4)$ & \\
\hline Unknown & $94(34)$ & $121(42.3)$ & \\
\hline \multicolumn{4}{|l|}{ History of pregnancies } \\
\hline No & $153(55.4)$ & $133(46.5)$ & \multirow{3}{*}{0.079} \\
\hline Yes & $123(44.6)$ & $150(55.4)$ & \\
\hline Unknown & $1(0.3)$ & $3(1.1)$ & \\
\hline \multicolumn{4}{|l|}{ HPV Genotype } \\
\hline 16/18 HPV & $66(23.8)$ & 39 (13.7) & \multirow{3}{*}{0.187} \\
\hline Other HR HPV & $51(18.4)$ & $42(14.7)$ & \\
\hline Non-HR HPV & $11(4.0)$ & $14(4.9)$ & \\
\hline \multicolumn{4}{|l|}{ Indication of conization } \\
\hline Persistent LSIN/CIN1 & $17(6)$ & $16(5.8)$ & \multirow[t]{2}{*}{0.908} \\
\hline HSIL/CIN 2-3 & $266(94)$ & $261(94.2)$ & \\
\hline \multicolumn{4}{|l|}{ Margin status } \\
\hline Negative & $221(79.8)$ & $239(83.5)$ & \multirow[t]{2}{*}{0.270} \\
\hline Positive & $56(20.2)$ & $47(16.6)$ & \\
\hline
\end{tabular}

\subsection{Characteristics of Vaccinated and Non-Vaccinated Women}

Overall, 277 (49.2\%) were vaccinated and $286(50.8 \%)$ were not. The mean age was 36.91 years (SD 8.15). Table 1 shows the clinical characteristics, the histological diagnosis of the conization specimen, and the margin status of the vaccinated and non-vaccinated women. No differences were found between the two groups. 


\subsection{Vaccination Scheme}

Of the 277 vaccinated women, $255(92.1 \%)$ received the three doses, 16 (5.8\%) received two doses, and $6(2.2 \%)$ received only one dose.

Among the vaccinated women, 67 (25.1\%) received the first dose prior to conization: $12(17.9 \%)$ received the first dose within 30 days before the intervention, $42(62.7 \%)$ between 1 to 9 months, and $13(19.4 \%)$ more than 9 months before conization.

Two hundred women were vaccinated after treatment: $14(7 \%)$ received the first dose the first month after conization, $135(67.8 \%)$ at between one and six months, and $51(25.12 \%)$ were vaccinated six months after treatment. Ten women were vaccinated during follow-up, but the dates were not reported.

\subsection{Results at 6-Month Follow-Up Visit}

The mean time from treatment to the first visit was 7.1 months (SD 8). The status at this control is shown in Table 2. Of 167 patients with HR-HPV infection, 106 (63.5\%) had normal cytology. The 10 women with persistent HSIL in the first post-conization visit underwent a second treatment after a HSIL/CIN 2-3 target biopsy.

Table 2. Status at six months in the vaccinated and non-vaccinated group. HPV: Human Papilloma Virus. HSIL: High-grade Squamous Intraepithelial Lesion. HR: High Risk. LSIL: Low-grade Squamous Intraepithelial Lesion.

\begin{tabular}{cccc}
\hline Status at $\mathbf{6}$ Months & $\begin{array}{c}\text { Vaccinated Group (\%) } \\
(\boldsymbol{n}=\mathbf{2 7 7 )}\end{array}$ & $\begin{array}{c}\text { Non-Vaccinated Group } \\
(\mathbf{\%})(\boldsymbol{n}=\mathbf{2 8 6})\end{array}$ & $p$ \\
\hline Cytology & & & \\
Negative & $239(86.3)$ & $246(86)$ & 0.490 \\
LSIL/ASCUS & $34(12.3)$ & $34(12.3)$ & \\
HSIL & $4(1.4)$ & $6(2.1)$ & \\
\hline HR-HPV testing & & $84(29.4)$ & \\
Positive & $83(30)$ & $202(70.6)$ & 0.657 \\
Negative & $194(70)$ & & \\
\hline Cotesting & & $195(68.2)$ & \\
Negative & $184(66.4)$ & $91(31.8)$ & \\
Positive ${ }^{1}$ & $93(33.6)$ &
\end{tabular}

${ }^{1}$ Positive co-testing indicates the presence of HR-HPV or abnormal cytology.

\subsection{Clinical Outcome at the End of Follow-Up}

The mean follow-up was 33.1 months (SD 17.60; median 32.9 months). For the vaccinated women, the mean follow-up was 29.6 months (SD 15.2; median 26.5 months), being 36.5 (SD 17.9; median 36.6 months) $(p<0.001)$ for the non-vaccinated women.

At the end of follow-up, 55 of 563 (9.8\%) women had persistent/recurrent HPV 16-18 infection. Persistent/recurrent infection was found in 28 of 286 (9.7\%) women in the nonvaccinated group and in $27 / 277(9.74 \%)$ women in the vaccinated group $(p=0.814)$. Figure 1 summarizes the distribution of patients and final outcome by time period (2009-2014 and 2015-2019). There was a tendency to lower HSIL/CIN 2-3 recurrence in the vaccinated group in comparison with the non-vaccinated group (See Figure 2).

Table $312 / 277(4.3 \%)$ vs. $28 / 286(9.8 \%), p<0.05)$. No differences were found when comparing HSIL/CIN 2-3 between the two groups considering only patients with no disease at the 6-month follow-up visit.

Considering only HSIL/CIN 2-3 recurrence associated with the vaccine genotype $(16 / 18)$, a lower non-significant recurrence rate was found in vaccinated women compared to non-vaccinated women: $8 / 277(2.9 \%)$ vs. $11 / 286(3.8 \%) ; p=0.529$. 


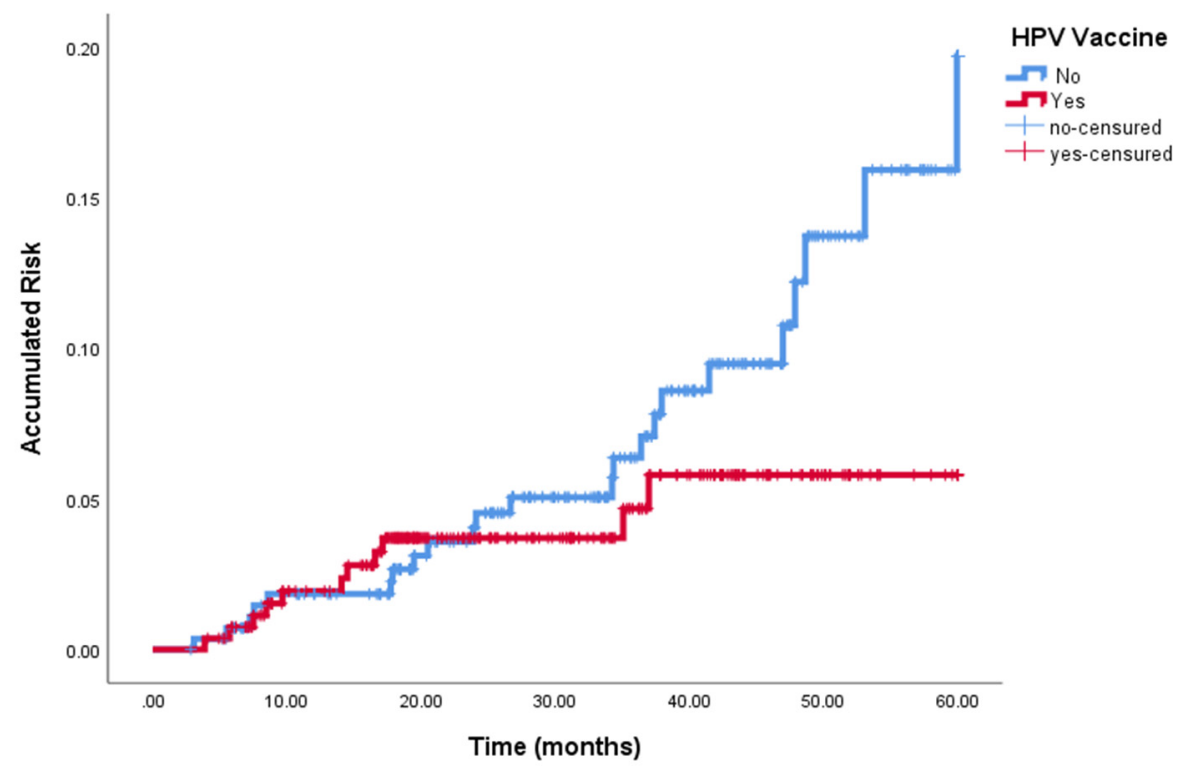

Figure 2. Persistent / Recurrent HSIL/CIN 2-3 in vaccinated and non-vaccinated women.

Table 3. Distribution and final clinical outcome of all women included in the study (A), and only women with no disease at 6-month follow-up visit (B). CIN: Cervical Intraepithelial Neoplasia HSIL: High Squamous Intraepithelial Lesion. LSIL: Low Squamous Intraepithelial Lesion; OR: odds ratio, CI: confidence interval.

\begin{tabular}{|c|c|c|c|}
\hline \multicolumn{4}{|c|}{ (A) 563 Conized Women with HSIL/CIN 2-3 } \\
\hline & $\begin{array}{c}\text { Vaccinated Women } \\
277(49.2 \%)\end{array}$ & $\begin{array}{c}\text { Non-Vaccinated Women } \\
286(50.8 \%)\end{array}$ & OR $(95 \% \mathrm{CI})$ \\
\hline No subsequent disease & $\begin{array}{c}206 \\
(74.4 \%)\end{array}$ & $\begin{array}{c}216 \\
(75.5 \%)\end{array}$ & 1 \\
\hline $\begin{array}{l}\text { Persistent/Recurrent } \\
\text { LSIL/CIN } 1\end{array}$ & $\begin{array}{c}59 \\
(21.3 \%)\end{array}$ & $\begin{array}{c}42 \\
(14.7 \%)\end{array}$ & $1.5(0.9-2.3)$ \\
\hline $\begin{array}{l}\text { Persistent/Recurrent } \\
\text { HSIL/CIN 2-3 }\end{array}$ & $\begin{array}{c}12 \\
(4.3 \%)\end{array}$ & $\begin{array}{c}28 \\
(9.8 \%)\end{array}$ & $0.4(0.2-0.9)^{1}$ \\
\hline \multicolumn{4}{|c|}{ (B) 379 Women Treated for HSIL/CIN 2-3 with No Disease at 6-Month Follow-Up Visit } \\
\hline & $\begin{array}{c}\text { Vaccinated Women } \\
184(48.5 \%)\end{array}$ & $\begin{array}{c}\text { Non Vaccinated Women } \\
195(51.4 \%)\end{array}$ & OR $(95 \% \mathrm{CI})$ \\
\hline No subsequent disease & $\begin{array}{c}161 \\
(87.5 \%)\end{array}$ & $\begin{array}{c}182 \\
(93.3 \%)\end{array}$ & 1 \\
\hline $\begin{array}{l}\text { Persistent/Recurrent } \\
\text { LSIL/CIN } 1\end{array}$ & $\begin{array}{c}21 \\
(11.4 \%)\end{array}$ & $\begin{array}{c}10 \\
(5.1 \%)\end{array}$ & $2.4(1.1-5.2)^{1}$ \\
\hline $\begin{array}{l}\text { Persistent/Recurrent } \\
\text { HSIL/CIN 2-3 }\end{array}$ & $\begin{array}{c}2 \\
(1.1 \%)\end{array}$ & $\begin{array}{c}3 \\
(1.5 \%)\end{array}$ & $0.7(0.1-4.5)$ \\
\hline
\end{tabular}

However, the two vaccinated women with HSIL/CIN 2-3 recurrence showed another genotype not included in the HPV vaccines: both women received the first dose of the vaccine one month after conization. The recurrence appeared 3 years later carrying an HPV 58 in the first woman and 2 years later carrying an HPV 33 in the second woman. On the other hand, when no disease was detected at the 6-month follow-up visit, the risk of recurrent HPV 16/18 infection decreased from 48/184 (26.1\%) to 7/379 (1.8\%) $(p<0.001)$. No differences were found in relation to recurrent HPV-16/18 infection between the vaccinated and non-vaccinated groups $(4 / 184(2.2 \%)$ vs. 3/195 (1.5\%), respectively).

Table 4 shows the univariate analysis for persistent/recurrent HSIL/CIN 2-3 at the end of follow-up. The factor associated with a low risk of persistent/recurrent HSIL/CIN 2-3 was the HPV vaccination status $(p=0.014)$, and the factor associated with a high risk of persistent/recurrent was the presence of a positive co-test at 6 months after conization $(p<0.001)$. 
Table 4. Univariate Cox regression analysis of risk factors associated with persistent/recurrent HSIL. SIL: squamous intraepithelial lesion; HR: Hazard ratio; CI: confidence interval; HR- HPV: high risk-human papillomavirus.

\begin{tabular}{|c|c|c|c|}
\hline \multirow[t]{2}{*}{ Variable } & \multicolumn{3}{|c|}{$\begin{array}{l}\text { Persistent/Recurrent HSIL/CIN 2-3 at the End of Follow-Up } \\
\text { (Univariate Analysis) }\end{array}$} \\
\hline & HR & $95 \% \mathrm{CI}$ & $p$ \\
\hline \multicolumn{4}{|l|}{ Age } \\
\hline$<35$ years & 1 & & 0.281 \\
\hline$\geq 35$ years & 0.70 & $0.37-1.37$ & \\
\hline \multicolumn{4}{|l|}{ Currently Smoke } \\
\hline No & 1 & & 0.367 \\
\hline Yes & 0.64 & $0.25-168$ & \\
\hline \multicolumn{4}{|l|}{ Presence of HR-HPV } \\
\hline No & 1 & & 0.340 \\
\hline Yes & 0.44 & $0.08-2.35$ & \\
\hline \multirow{2}{*}{\multicolumn{4}{|c|}{$\begin{array}{l}\text { Margin in conization } \\
\text { specimen }\end{array}$}} \\
\hline & & & 0.475 \\
\hline Negative & 1 & & \\
\hline Positive & 1.30 & $0.63-2.70$ & \\
\hline \multicolumn{4}{|l|}{ Vaccination Status } \\
\hline No & 1 & & 0.014 \\
\hline Yes & 0.42 & $0.21-0.84$ & \\
\hline \multicolumn{4}{|c|}{ 6-month follow-up visit } \\
\hline Negative co-test & & & 0.001 \\
\hline Positive co-test & 22.62 & $7.91-64.67$ & \\
\hline
\end{tabular}

\section{Discussion}

To our knowledge, this is the largest Spanish study to evaluate the effect of the HPV vaccine in women treated for HSIL/CIN 2-3 in clinical practice with the same follow-up protocol. The results of our study support the use of HPV vaccination to reduce the risk of developing persistent/recurrent HSIL/CIN 2-3 after surgical treatment.

Several studies $[8,9,11]$ have shown that HPV vaccination in women undergoing conization for HSIL/CIN 2-3 can reduce the risk of developing subsequent disease. The SPERANZA was the first prospective study evaluating the clinical effectiveness of the HPV vaccine in reducing HSIL/CIN 2+, with a recurrence risk reduction of $81.2 \%$. In our study, although the HSIL/CIN 2-3 rate was significantly lower in the vaccinated group, we found a risk reduction of $57 \%$, similar to the $59 \%$ published in the meta-analysis by Jentschke [14]. Gomez de la Rosa et al. reported an intermediate relative risk of 73.5\% [18]. The protective effect of the HPV vaccine was particularly clear against HSIL/CIN 2-3 lesions, since HPV 16/18 was present in only $20 \%$ of low-grade lesions. Our LSIL/CIN 1 rates were similar to those of del Pino et al. [11], with no differences between the vaccinated and non-vaccinated groups.

While it has been hypothesized that the HPV vaccine could evoke local antibodies that prevent virus entrance in the basal layer [8], the effectiveness of prophylactic HPV vaccination against prevalent infection has not been demonstrated [19-21]. Our data suggest that the HPV vaccine does not reduce the risk of persistent/recurrent HPV infection (neither genotype 16/18) $(p=0.814)$, according to the findings of del Pino et al. [11]. However, our study found a lower rate of high-grade lesional recurrence associated with the HPV 16-18 genotypes in the vaccinated group, albeit without significant differences between groups. This result may be due to the low number of affected patients and would probably be considered more significant with a larger patient sample. Therefore, recurrence associated with vaccine genotypes only should be studied in greater depth. 
Persistent HSIL at the 6-month follow-up visit was similar in both groups (4/277 [1.4\%] in the vaccinated vs. $6 / 286[2.1 \%]$ in the non-vaccinated group). This could be explained, first of all, because the vaccine does not have a therapeutic but a prophylactic effect, and, in the second place, due to the fact that antibody titres have a maximum peak 7 months after the administration of the first dose [22,23] and most of our patients received the first dose of the HPV-vaccine after conization; thus, vaccination was not completed until 6 months after treatment. On the other hand, data available show excellent duration of the protection for the time periods through which they have been studied. Persistent antibody levels and protection against HPV infection have also been reported up to 14 years following vaccination, suggesting no need for a booster dose during that period [24]. However, the precise level of antibodies required for protection against infection is unknown, so further studies are necessary. In this regard, our results show that the HPV vaccine reduces lesion recurrence at least 5 years after administration. No-disease at the 6-month follow-up visit is related to a decrease in lesion recurrence and HPV infection, however, although in the future a different follow-up strategy could be proposed for vaccinated patients with a negative cotest at 6 months post-treatment; to date, there is not enough scientific evidence to make changes to the clinical guidelines. Interestingly, in the present series, all the women showed a very low rate of recurrent HPV infection and recurrent HSIL/CIN 2-3 regardless of vaccination status.

The strength of our study includes the large size of the cohort and the long follow-up period following the same protocol. In addition, our study showed low rates of positive margins and positive co-tests at the 6-month follow-up visit, according to the quality standards of the Colposcopy Unit. Correct patient treatment could justify the low percentage of persistent/recurrent lesions regardless of vaccination status. On the other hand, some limitations must be taken into account: women were vaccinated at different time points, not all women received the full vaccination schedule, and, due to the retrospective nature of the study, the vaccination type (2v-HPV or $4 \mathrm{v}-\mathrm{HPV})$ could not be analyzed. In addition, we cannot be sure that no women returned to the screening program, presented late recurrence, and were evaluated another hospital. Finally, another limitation is that the mean length follow-up was shorter in the vaccinated group because very few women were vaccinated before 2015.

\section{Conclusions}

In conclusion, this study corroborates the benefit of HPV vaccination in women treated for HSIL/CIN 2-3, showing that HPV vaccination is associated with a reduction in the risk of persistent/recurrent HSIL/CIN 2-3 after conization and that the factor associated with a high risk of persistent/recurrent HSIL/CIN 2-3 is to have abnormal pap-smear results and/or a positive HR-HPV genotype at the first control after treatment.

Author Contributions: A.C.-P., M.R.-M. and P.J.C.-M. have developed the study design and analyzed the statistical results. A.C.-P., M.R.-M., E.R.-P., I.G.-P., J.G.-S., M.B.-d.A., J.J.H.-A., J.d.l.F.-V., I.Z., P.J.C.-M. contributed to critical review of the paper. A.C.-P., M.R.-M., E.R.-P., I.G.-P., J.G.-S., M.B.-d.A., J.J.H.-A., J.d.l.F.-V., I.Z., P.J.C.-M. All authors have read and agreed to the published version of the manuscript.

Funding: Supported in part by research grant from Investigator-Initiated Studies program of Merck Sharph \& Dohme Corp [Project number: IISP 59385, 2019]. The opinions expressed in this papel are those of the authors and do not necessarily represent those of Merck Sharph \& Dohme Corp.

Institutional Review Board Statement: The study was conducted according to the guidelines of the Declaration of Helsinki and approved by Ethics Committee of Hospital Clínico San Carlos (protocol code 19/320-E; 14 September 2020).

Informed Consent Statement: Informed consent was obtained from all subjects involved in the study.

Data Availability Statement: The datasets generated and analyzed during the current study are available from the corresponding author upon reasonable request. 


\begin{abstract}
Acknowledgments: We thank Donna Pringle for English revision of the article and Irene Serrano y Rafael Sánchez for the statistical analysis.

Conflicts of Interest: M.R.-M. has received personal fees from Merck Sharph \& Dohme (MSD) and GlaxoSmithKline (GSK) for scientific advisory and committee meetings and speaking fees from MSD. P.J.C.-M. has received personal fees from MSD and GSK for conducting clinical HPV vaccine trials, scientific advisory committee meetings and speaking fees. J.J.H.-A. and J.d.l.F.-V. have received personal fees from MSD and GSK for scientific advisory and committee meetings and speaking fees from MSD. The remaining authors have no disclosures. The authors declare that they have no known competing financial interests or personal relationships that could have influenced the work reported in this paper.
\end{abstract}

\title{
References
}

1. Schlecht, N.F.; Kulaga, S.; Robitaille, J.; Ferreira, S.; Santos, M.; Miyamura, R.A.; Duarte-Franco, E.; Rohan, T.E.; Ferenczy, A.; Villa, L.L.; et al. Persistent human papillomavirus infection as a predictor of cervical intraepithelial neoplasia. JAMA 2001, 286, 3106-3114. [CrossRef] [PubMed]

2. Van Dyne, E.A.; Henley, S.J.; Saraiya, M.; Thomas, C.C.; Markowitz, L.E.; Benard, V.B. Trends in Human Papillomavirus-Associated Cancers United States, 1999-2015. MMWR Morb. Mortal. Wkly. Rep. 2018, 67, 918-924. [CrossRef] [PubMed]

3. Baker, P.; Kelly, D.; Medeiros, R. Viral Protection: A Four Step Plan for Eliminating HPV Cancers in Europe; European Cancer Organisation: Brussels, Belgium, 2020.

4. Torné, A.; Secretaria, D.; Pino, M.; Alameda, F.; Andía, D.; Castellsagué, X. AEPCC-Guía: Prevención del Cáncer de Cuello de Útero; Publicaciones AEPCC: Madrid, Spain, 2015.

5. Torné, A.; Secretaria, D.; Pino, M.; Autores, T.A.; Andía, D.; Bruni, L.; Centeno, C.; Coronado, P.; Cruz Quílez, J.; de la Fuente, J.; et al. AEPCC-Guía: Prevención Secundaria del Cancer de Cuello del Útero, Conducta Clínica Anteresultados Anormales de Las Pruebas de Cribado; Publicaciones AEPCC: Madrid, Spain, 2022.

6. Ochoa-Carrillo, F.J. Virus del papiloma humano. Desde su descubrimiento hasta el desarrollo de una vacuna. Parte I/III. Gac. Mex. Oncol. 2014, 13, 308-315.

7. Torné Bladé, A.; del Pino Saladrigues, M.; Cusidó Gimferrer, M.; Ponce Sebastià, J. Oncoguía SEGO: Prevención del cáncer de cuello de útero. In Guías de Práctica Clínica en Cáncer Ginecológico y Mamario; Publicaciones SEGO: Spain, 2014.

8. Kang, W.D.; Choi, H.S.; Kim, S.M. Is vaccination with quadrivalent HPV vaccine after loop electrosurgical excision procedure effective in preventing recurrence in patients with high-grade cervical intraepithelial neoplasia (CIN2-3)? Gynecol. Oncol. 2013, 130, 264-268. [CrossRef] [PubMed]

9. Ghelardi, A.; Parazzini, F.; Martella, F.; Pieralli, A. SPERANZA project: HPV vaccination after treatment for CIN2+. Gynecol. Oncol. 2018, 151, 229-234. [CrossRef] [PubMed]

10. Velentzis, L.S.; Brotherton, J.M.L.; Canfell, K. Recurrent disease after treatment for cervical pre-cancer: Determining whether prophylactic HPVvaccination could play a role in prevention of secondary lesions. Climacteric 2019, 22, 596-602. [CrossRef] [PubMed]

11. Del Pino, M.; Martí, C.; Torras, I.; Henere, C.; Munmany, M.; Marimon, L.; Saco, A.; Torné, A.; Ordi, J. HPV Vaccination as Adjuvant to Conization in Women with Cervical Intraepithelial Neoplasia: A Study under Real-Life Conditions. Vaccines 2020, 8, 245. [CrossRef] [PubMed]

12. Saftlas, A.F.; Spracklen, C.N.; Ryckman, K.K.; Stockdale, C.K.; Penrose, K.; Ault, K.; Rubenstein, L.M.; Pinto, L.A. Influence of a loop electrosurgical excision procedure (LEEP) on levels of cytokines in cervical secretions. J. Reprod. Immunol. 2015, 109, 74-83. [CrossRef] [PubMed]

13. Scott, M.E.; Shvetsov, Y.B.; Thompson, P.J.; Hernandez, B.Y.; Zhu, X.; Wilkens, L.R.; Killeen, J.; Vo, D.D.; Moscicki, A.B.; Goodman, M.T. Cervical cytokines and clearance of incident human papillomavirus infection: Hawaii HPV cohort study. Int. J. Cancer 2013, 133, 1187-1196. [CrossRef] [PubMed]

14. Jentschke, M.; Kampers, J.; Becker, J.; Sibbertsen, P.; Hillemanns, P. Prophylactic HPV vaccination after conization: A systematic review and meta-analysis. Vaccine 2020, 38, 6402-6409. [CrossRef] [PubMed]

15. Servicio de Prevención de la Enfermedad. Calendario de Vacunación del Adulto; Dirección General de Salud Pública. Consejería de Sanidad Comunidad de Madrid: Madrid, Spain, 2019.

16. Puig-Tintoré, L.M.; Cortés, J.; Castellsagué, X.; Torné, A.; Ordi, J.; de San José, S.; Alonso, I.; Cararach, M.; Vidart, J.A.; Alba, A. Prevención del cáncer de cuello uterino ante la vacunación frente al virus del papiloma humano. Prog. Obs. Ginecol. 2006, 49, 5-62.

17. Genomica: Línea CLART ${ }^{\circledR}$ HPV [internet]. Available online: https://genomica.com/linea-clart-hpv (accessed on 14 April 2016).

18. Gómez de la Rosa, A.G.; Quesada López-Fe, A.; Vilar Chesa, M.; Ferrer Machín, A.; Gimeno Gil, A.; Molina Bethancourt, A.; García Bello, M.Á.; Pérez-Méndez, L.I. Efficacy of Human Papillomavirus Vaccination 4 Years After Conization for High-Grade Cervical Neoplasia. J. Low. Genit. Tract Dis. 2021, 25, 287-290. [CrossRef] [PubMed]

19. Joura, E.A.; Giuliano, A.R.; Iversen, O.E.; Bouchard, C.; Mao, C.; Mehlsen, J.; Moreira, E.D.J.; Ngan, Y.; Petersen, L.K.; LazcanoPonce, E.; et al. A 9-valent HPV vaccine against infection and intraepithelial neoplasia in women. N. Engl. J. Med. 2015, 372, 711-723. [CrossRef] [PubMed] 
20. The Future II Study Group. Quadrivalent vaccine against human papillomavirus to prevent high-grade cervical lesions. N. Engl. J. Med. 2007, 356, 1915-1927. [CrossRef] [PubMed]

21. Cox, J.T.; Palefsky, J.M. Human Papillomavirus Vaccination. Available online: https://www.uptodate.com/contents/humanpapillomavirus-vaccination (accessed on 10 February 2022).

22. Hildesheim, A.; Wacholder, S.; Catteau, G.; Struyf, F.; Dubin, G.; Herrero, R.; CVT Group. Efficacy of the HPV-16/18 vaccine: Final according to protocol results from the blinded phase of the randomized Costa Rica HPV-16/18 vaccine trial. Vaccine 2014, 32, 5087-5097. [CrossRef] [PubMed]

23. Einstein, M.H.; Takacs, P.; Chatterjee, A.; Sperling, R.S.; Chakhtoura, N.; Blatter, M.M.; Lalezari, J.; David, M.P.; Lin, L.; Struyf, F.; et al. Comparison of long-term immunogenicity and safety of human papillomavirus (HPV)-16/18 AS04-adjuvanted vaccine and HPV-6/11/16/18 vaccine in healthy women aged 18-45 years: End-of-study analysis of a Phase III randomized trial. Hum. Vaccines Immunother. 2014, 10, 3435-3445. [CrossRef] [PubMed]

24. Kjaer, S.K.; Nygård, M.; Sundström, K.; Dillner, J.; Tryggvadottir, L.; Munk, C.; Berger, S.; Enerly, E.; Hortlund, M.; Ágústsson, Á.I.; et al. Final analysis of a 14-year long-term follow-up study of the effectiveness and immunogenicity of the quadrivalent human papillomavirus vaccine in women from four nordic countries. EClinicalMedicine 2020, 23, 100401. [CrossRef] [PubMed] 